\title{
LA GARANTÍA DEL ESTADO FRENTE A LA CRISIS ECONÓMICA ${ }^{1}$
}

\author{
JoRge GARCÍA-ANDRADE GÓmeZ \\ Profesor de Derecho Administrativo \\ Universidad de Alcalá
}

\begin{abstract}
RESUMEN
Durante la crisis económica el Estado ha rescatado empresas y entidades territoriales mediante el otorgamiento de garantías pecuniarias. Esta utilización intensiva de los avales públicos exige una revisión de su normativa reguladora, concebida para tiempos de normalidad económica, al tiempo que trastoca las relaciones entre los poderes garantes y las empresas y autoridades rescatadas.

Palabras clave: garantías públicas; avales públicos; rescates públicos; economía de mercado; principio de sostenibilidad económica.

ABSTRACT

During the economic crisis public authorities have bailed out companies and other authorities by granting financial guarantees. This intensive use of government guarantees requires a revision of its regulation, which was designed for times of economic normality. Meanwhile, it disrupts relations between the guarantor powers and the bailed-out institutions.
\end{abstract}

Keywords: government guarantees; public collateral; public bailouts; market economy; economic sustainability.

\footnotetext{
1 Este trabajo se inserta en el proyecto de investigación «El Estado garante. Un nuevo modelo para afrontar los presentes retos sociales y económicos del Estado del bienestar» (DER2015-65223-C3-1-R) y se ha enriquecido con las sugerencias del Consejo de Redacción de la $R A P$ y sus evaluadores anónimos, así como de los compañeros con los que he tenido la oportunidad de discutirlo, a quienes se lo agradezco.
} 


\section{SUMARIO}

I. Planteamiento. - - II. Concepto y tipología de las garantías públicas: 1. Concepto de las garantías públicas. 2. Diferenciación respecto de categorías próximas: A) El llamado Estado garante. B) Las garantías como compromisos de actuación futura de los órganos del Estado. 3. Tipología de las garantías públicas: A) Avales. B) Seguros. C) Fondo de Garantía Salarial. D) Garantías en el sector financiero. E) La mal llamada responsabilidad patrimonial. F) Garantías al alquiler.-III. LA GARANTÍA DEL ESTADO EN EL DERECHO DE EMERGENCIA ECONómica. - - IV. Problemática JuRídica de la actuación Garante del Estado: 1. Consideración de las garantías públicas como recursos escasos de la Administración. 2. La incertidumbre como premisa del aval. 3. El principio de legalidad ante el otorgamiento de garantías implícitas, informales o de importe indeterminado. 4 . El principio constitucional de sostenibilidad económica como límite a la garantía del Estado. - V. INCIDENCIA DE LAS GARANTÍAS PÚBliCAS SOBRE LA RELACIÓN ESTADO-SOCIEDAD: 1. Los rescates públicos como modernos títulos de intervención. 2. Los rescates públicos y la cláusula de "economía de mercado».

\section{Planteamiento}

Entre las muchas y aceleradas transformaciones que la actual crisis económica nos está deparando debe anotarse la que ha convertido a los Estados en garantes de buena parte de sus economías e incluso de las ajenas. Esta novedosa situación trae causa de los avales y otras garantías pecuniarias que los Estados han otorgado masivamente en favor de sectores enteros de la economía, de entidades territoriales y de otros Estados, ante las dudas suscitadas sobre la capacidad de todos estos últimos para atender las obligaciones de pago que previamente habían contraído.

La reacción frente a la crisis económica ha alterado la finalidad con la que el Estado había empleado tradicionalmente el aval público. Si hasta entonces esta figura jurídica había servido esencialmente como un instrumento de la acción administrativa de fomento, ahora se caracteriza por su mayor versatilidad, al haber permitido que el Estado acometa también el rescate de sectores económicos e instituciones públicas en riesgo de insolvencia. Las razones para la utilización a gran escala del aval público deben buscarse en su sencillez y en que permite operaciones de rescate económico sin necesidad de disponer de manera inmediata de fondos públicos, ni por tanto de recurrir al endeudamiento o la elevación de impuestos. De forma que en una situación de graves estrecheces presupuestarias y de pérdida generalizada de confianza en la solvencia de muy distintos operadores, la figura del aval público ha emergido con un papel protagonista que históricamente no había conocido. 
Las garantías públicas alcanzan tal dimensión que han llegado a comprometer la propia viabilidad económica de algunos Estados ${ }^{2}$. En España las sucesivas leyes de presupuestos generales del Estado registran con precisión la magnitud del fenómeno: si los presupuestos previos a la irrupción de la crisis autorizaban un importe máximo de avales de unos 220 millones de euros, cerca del $0,075 \%$ de los gastos presupuestados (arts. 2 y 52 de la Ley 42/2006); en los momentos de mayor intensidad de la crisis, la partida de avales llegó a superar los 313000 millones de euros, más del $100 \%$ de los gastos presupuestados (arts. 2 y 52 de la Ley 2/2012). Estos datos reflejan cómo la utilización de los avales públicos ha pasado de ser escasamente significativa a multiplicarse exponencialmente ${ }^{3}$.

Si se analiza jurídicamente el fenómeno se observa que estas operaciones masivas de rescate mediante avales públicos tienen importantes implicaciones para el derecho público. De una parte, cabe cuestionarse si la lacónica regulación de los avales públicos contenida en el derecho español es suficiente para soportar una operativa estatal de tales magnitudes o si, por el contrario, urge la revisión del régimen jurídico de las garantías patrimoniales que puede prestar el Estado. Por otro lado, este tipo de rescates altera el sistema de relaciones entre el Estado y la sociedad, que se proyecta en una intervención administrativa más intensa sobre los sectores rescatados, un mayor control de unas entidades públicas sobre otras y la modulación de alguno de los postulados de la economía de mercado.

La identificación del fenómeno enunciado, así como el análisis de su incidencia en el derecho público en los aspectos que acaban de señalarse, constituyen el objeto del presente estudio.

\section{CONCEPTO Y TIPOLOGÍA DE LAS GARANTÍAS PÚBliCAS}

\section{Concepto de las garantías públicas}

El concepto de garantía puede resultar muy equívoco, dada su amplitud y riqueza, por lo que es conveniente acotar el sentido con el que se emplea en el presente trabajo. Como punto de partida, la acepción del térmi-

2 Es el caso de Irlanda que, como respuesta a la desconfianza financiera, el 29 de noviembre de 2008 garantizó la devolución de los depósitos y otras obligaciones de las principales entidades bancarias. La garantía otorgada duplicaba en su importe el PIB del país, lo que resultaba inasumible para las finanzas públicas irlandesas y contribuyó decisivamente a que el país hubiera de solicitar un rescate de sus socios europeos en 2010.

3 Téngase además en cuenta que las leyes de presupuestos solo reflejan las autorizaciones para el otorgamiento de nuevos avales en cada ejercicio, pero no consta en ellas el importe vivo acumulado de los avales otorgados a lo largo de los años. 
no garantía que más interesa es la cultivada en el derecho privado, donde disfruta de una notable sedimentación y de una delimitación conceptual bastante precisa. Junto a ella, también se analizarán las inevitables modulaciones que el derecho administrativo incorpora a la garantía civil, en el sentido que explicó S. MARTín-Retortillo ${ }^{4}$. En particular, el impacto de la crisis económica exige ampliar el concepto de garantía pública para así poder explicar la posición en la que queda el Estado cuando de manera sobrevenida se ve en la necesidad de financiar o asumir el pago de compromisos que no le correspondían y no había respaldado explícitamente, abriéndose de esta manera un significado adicional que solo tiene sentido en el campo del derecho público. Tanto las modulaciones administrativas a la categoría civil como la ampliación del concepto en el derecho público son objeto de análisis en otros epígrafes, por lo que debe retomarse ahora la acepción civil de la garantía.

La garantía se utiliza aquí en su sentido estrictamente pecuniario o patrimonial, lo que permite establecer una primera línea divisoria con respecto a otras figuras nacidas en el derecho administrativo que tienen una significación claramente diferenciada, referida a la función regulatoria o a compromisos de actuación pública (véase infra la diferenciación respecto de categorías próximas).

Así considerada, la garantía civil es el instrumento jurídico con el que se asegura la efectividad de un crédito. Constituye, por tanto, un refuerzo para el acreedor, que ve incrementadas las posibilidades del cobro de su crédito $^{5}$. Este refuerzo patrimonial podrá consistir en la afectación y protección de determinados bienes al pago de la deuda, como ocurre con las garantías reales: prenda o hipoteca; o en la posibilidad de reclamar el pago también de un tercero distinto del deudor, como ocurre con el aval. Por tanto, la garantía puede predicarse tanto de las propias obligaciones como de las ajenas.

Este es el sentido tradicional y más extendido de garantía en el derecho civil, lo que lleva a descartar ciertas cláusulas contractuales del derecho mercantil como las llamadas «manifestaciones y garantías» que consisten en declaraciones solemnes de una de las partes contratantes sobre determinados hechos (generalmente adveran el estado o características del bien o derecho objeto del contrato) y cumplen una función

\footnotetext{
4 S. Martín-Retortillo (1996), El Derecho civil en la génesis del Derecho administrativo y de sus instituciones, Madrid: Civitas, págs. 47-54.

5 L. Díez-Picazo (1993), Fundamentos del Derecho civil patrimonial. II Las relaciones obligatorias, Madrid: Civitas (págs. 395 y ss.); y Á. Carrasco Perera, E. Cordero Lobato y M. J. Marín López (2015), Tratado de los Derechos de Garantía, vol. I, Cizur Menor: Aranzadi (págs. 79-81).
} 
informativa y de atribución de responsabilidad ${ }^{6}$, pero no aportan un refuerzo a la posición del acreedor respecto del cumplimiento de la obligación contraída.

Para el fenómeno que aquí se analiza interesan fundamentalmente las garantías pecuniarias en sentido estricto y que se predican respecto de las obligaciones ajenas. Esto es, se dejan fuera del estudio las garantías que el Estado o la Administración puedan ofrecer para el cumplimiento de sus propias obligaciones, como por ejemplo el compromiso del Estado de indemnización de los daños que sufran las obras de arte cedidas para la exhibición en sus museos e instituciones culturales (disposición adicional novena de la Ley 16/1985, de 25 de junio, del Patrimonio Histórico Español) o la cláusula constitucional de la prioridad absoluta en el pago de la deuda pública que recoge el artículo $135^{7}$.

Debe añadirse que el concepto de garantía comprende muy diversas manifestaciones y negocios jurídicos típicos: prendas, hipotecas, avales, seguros de caución, cartas de patrocinio, reservas de dominio, arrendamientos financieros, además de clasificarse en garantías reales o personales $^{8}$. En todos ellos se refuerza el cumplimiento de una obligación en beneficio del acreedor con vistas al cobro de su crédito. Pero no todas ellas interesan al derecho administrativo, pues la Administración solo se sirve en su tráfico habitual de algunas de aquellas figuras, así como conforma otras nuevas que no tienen una exacta correspondencia en el derecho privado, por lo que este estudio se centra únicamente en aquellas que son relevantes para el Derecho administrativo.

Por último, no puede perderse de vista el sentido último de las garantías públicas. Estas descansan en la mayor reputación de solvencia de la Administración de que se trate frente al sujeto garantizado que requiere de un refuerzo patrimonial en el tráfico jurídico.

6 J. Aguayo (2011), Las manifestaciones y garantías en el Derecho de contratos español, Madrid: Civitas (págs. 37, 124 y 179). Con esta acepción se emplean en la cláusula 5 del «Acuerdo marco de asistencia financiera entre la Facilidad Europea de Estabilización Financiera, el Reino de España como Estado miembro beneficiario, el Fondo de Reestructuración Ordenada Bancaria como garante y el Banco de España» [Memorando de entendimiento entre la Comisión Europea y España» (BOE 10.X. 2012)].

7 La garantía que proporciona esta cláusula deriva de la prelación de créditos que establece, al otorgar preferencia a los acreedores de deuda pública: J. García-Andrade Gómez (2013), «La adopción de la estabilidad presupuestaria en la Constitución española», en Ius Publicum Network Review, 3/4, págs. 1-69 (págs. 37 y ss.).

8 L. Díez-Picazo (1993: 461 y ss.) y Á. Carrasco Perera et al. (2015). 


\section{Diferenciación respecto de categorías próximas}

Así delimitado el concepto de garantía del Estado que aquí interesa analizar, es también aconsejable diferenciarlo de otras categorías próximas que son empleadas en el derecho administrativo.

\section{A) El llamado Estado garante}

La primera de ellas se refiere a la función del Estado garante que encierra una idea muy próxima a la que aquí interesa, si bien responde a unos presupuestos y dinámica propios. La teoría sobre el Estado garante tiene su origen en el derecho alemán ${ }^{9}$, de donde ha sido tomada por un sector de la doctrina española ${ }^{10}$. Conforme a este planteamiento, el Estado garante describe la posición en que se encuentran el Estado y la Administración a resultas de su retraimiento respecto del modelo organizativo que caracterizó la segunda mitad del siglo pasado, en el que la Administración asumía la prestación directa de ciertos servicios y atenciones en favor de los ciudadanos. El proceso de profundización en el mercado interior europeo, unido a la liberalización económica de los años noventa, dieron como resultado que muchos de aquellos servicios, fundamentalmente los de interés económico general, pasasen a ser prestados por operadores privados en régimen de competencia. No obstante, la importancia de aquellos servicios en la sociedad contemporánea siguió justificando una intervención intensa del Estado respecto de la forma y condiciones de su prestación, con vistas a garantizar la accesibilidad, la calidad y el acceso universal a ellos (art. 14 y protocolo núm. 26 TFUE). Así las cosas, el Estado habría dejado de ser prestador de los servicios para convertirse en garante de su disponibilidad en favor de los ciudadanos.

En cuanto a las técnicas propias del Estado garante, los autores coinciden en que básicamente consisten en la regulación de la actividad pri-

\footnotetext{
9 W. Hoffmann-Riem (2001), Modernisierung von Recht und Justiz. Eine Herausforderung des Gewährleistungsstaates, Frankfurt am Main: Suhrkamp; M. Knauff (2004), Der Gewährleistungsstaat: Reform der Daseinsvorsorge, Berlin: Dunker \& Humblot; G. F. ScHuPPERT (dir.) (2005), Der Gewährleistungs-staat-Ein Leitbild auf dem Prüfstand, Baden-Baden: Nomos.

10 J. Esteve Pardo (2013), «La evolución del garantismo: de las garantías personales a la garantía del Estado. La reforma constitucional para la estabilidad presupuestaria y contención del déficit», en Revista Catalana de Dret Públic, 46, págs. 1-13; (2015a) «La Administración garante. Una aproximación», en Revista de Administración Pública, 197, págs. 11-39; (2015b), Estado garante: idea y realidad, Madrid: INAP.
} 
vada $^{11}$, entendida en su sentido anglosajón y no meramente normativo, pues comprende desde el establecimiento de obligaciones de servicio público, pasando por la intervención administrativa en los precios, la supervisión, inspección, etc. ${ }^{12}$.

Esta concepción del Estado garante no coincide en su planteamiento, finalidad ni en sus técnicas de intervención con las garantías de contenido patrimonial que aquí se analizan. En la construcción del Estado garante la Administración pública no avala el cumplimiento de obligaciones pecuniarias que correspondían a terceros sujetos. Como tampoco se prevé que los usuarios de los servicios de interés económico general puedan dirigirse subsidiariamente a la Administración «garante» para que realice de manera directa las prestaciones debidas por los operadores económicos. A pesar de que la utilización de los términos "garantía» y «garante» puedan inducir a establecer tales conexiones, el Estado garante no alumbra relaciones obligatorias de contenido pecuniario entre los usuarios y la Administración pública ${ }^{13}$.

B) Las garantías como compromisos de actuación futura de los órganos del Estado

En el ámbito de las relaciones internacionales no es infrecuente que los Estados asuman "garantías» de distinto contenido frente a otros Estados, instituciones europeas e incluso organizaciones privadas. Muchas de esas garantías tienen un contenido patrimonial en el sentido que aquí se analiza, pero bajo la misma denominación se encierran también compromisos que asumen algunos poderes del Estado frente a la otra

11 M. Darnaculleta i Gardella (2009), «La recepción y desarrollo de los conceptos y fórmulas de la regulación. El debate en la República Federal Alemana», en S. MuÑoz Machado y J. Esteve Pardo (dirs.), Fundamentos e instituciones de la regulación, Madrid: Iustel, págs. 349-386 (págs. 384 y ss.); y J. L. CARRo Fernández-Valmayor (2014), "Reflexiones sobre las transformaciones actuales del Derecho Público, en especial del Derecho administrativo", en Revista de Administración Pública, 193, págs. 11-44, (35).

12 J. Esteve Pardo (2015a: 30 y ss.).

13 El limitado alcance de la "garantía»se podía leer en el derogado artículo 10 de la Ley 2/2011, de 4 de marzo, de Economía Sostenible, que se hizo eco de aquella formulación académica: «Los Organismos Reguladores tendrán como objeto prioritario de su actuación velar por el adecuado funcionamiento del sector económico regulado para garantizar la efectiva disponibilidad y prestación de unos servicios competitivos y de alta calidad en beneficio del conjunto del mercado y de los consumidores y usuarios». El vigente artículo 2 de la Ley 3/2013, de 4 de junio, de creación de la Comisión Nacional de los Mercados y la Competencia, mantiene la referencia a aquella función de garantía: «La Comisión Nacional de los Mercados y la Competencia tiene por objeto garantizar, preservar y promover el correcto funcionamiento, la transparencia y la existencia de una competencia efectiva en todos los mercados y sectores productivos, en beneficio de los consumidores y usuarios». 
parte y cuyo objeto atañe al ejercicio de las potestades públicas por parte de distintos órganos y entidades del Estado.

Así en el «Memorando de entendimiento», suscrito para que España pudiera recibir el rescate de la Unión Europea (UE) en 2012, el Estado otorgaba una «Garantía de un marco sólido para el sector bancario: condicionalidad horizontal», que se desglosaba en compromisos sobre la modificación del ordenamiento jurídico español, el ejercicio de la supervisión financiera por las autoridades públicas o el perfeccionamiento de ciertos registros públicos (apartado V).

También en la competición internacional para lograr la adjudicación de la celebración de acontecimientos deportivos, como los Juegos Olímpicos, los poderes públicos asumen garantías por las que se comprometen a mantener un determinado régimen de autorizaciones, a ejercer la potestad normativa con un determinado resultado o la realización de obras públicas ${ }^{14}$. Como ha señalado C. Chinchilla este tipo de garantías ofrece muchas dudas acerca de su naturaleza jurídica y, más concretamente, acerca de su exigibilidad o carácter vinculante, tanto por razones de atribución de competencias —no se compromete el Estado como persona jurídica internacional, sino una ciudad, órgano autonómico o estatal-, como por el propio contenido de la obligación asumida. Hasta el punto de que aquella autora se pregunta acerca su auténtica condición jurídica de garantías ${ }^{15}$, como también cabría cuestionarse respecto de la actuación garante del Estado tomada del derecho alemán.

En cualquier caso, lo cierto es que se ha extendido su denominación como un tipo concreto de garantías, cuyo objeto consiste en el compromiso de ejercer las potestades públicas en un determinado sentido. Por lo que conviene aclarar que por su finalidad, objeto y naturaleza jurídica claramente difieren del tipo de actuación garante que aquí se analiza, en cuya virtud la Administración pública afianza el cumplimiento de la obligación pecuniaria de otro sujeto.

\section{Tipología de las garantías públicas}

En su quehacer ordinario, la Administración se ha servido de una rica tipología de garantías públicas con las que respalda el cumplimien-

14 Tomo los ejemplos de la obra de C. Chinchilla Marín (2009), Los Juegos Olímpicos: la elección de la sede y otras cuestiones jurídicas, Cizur Menor: Civitas (pág. 330), pues, como señala esta autora, el llamado «Dossier de Garantías», cuya suscripción exige la entidad promotora de los Juegos Olímpicos, no tiene carácter público.

15 C. Chinchilla Marín (2009: 337 y ss. y 341 y ss.). 
to de obligaciones pecuniarias de terceros. A continuación se ofrece, sin ánimo exhaustivo, una enunciación de sus principales manifestaciones para que pueda contribuir a formar una imagen ajustada de esta realidad de la actividad administrativa. La enunciación se ciñe al tipo de garantías empleadas por la Administración en tiempos de normalidad económica, mientras que en el epígrafe siguiente se abordará la transformación que ha experimentado la actividad garante de la Administración a resultas de la gran crisis económica.

\section{A) Avales}

Por su importancia cuantitativa, el primer lugar corresponde a los avales públicos regulados en la Ley 47/2003, de 26 de noviembre, General Presupuestaria (LGP).

La LGP emplea el término aval como el instrumento con el que la Administración puede «afianzar las obligaciones derivadas de operaciones de crédito concertadas en el interior o en el exterior por personas naturales o jurídicas, públicas o privadas» (art. 113), pero no lo define, por lo que es necesario acudir supletoriamente a las normas de derecho común (art. 4.3). El artículo 1822 del Código Civil (CC) define la fian$\mathrm{za}^{16}$ como la figura por la que «se obliga uno a pagar o cumplir por un tercero, en el caso de no hacerlo este». Existe por tanto una diferencia entre ambas figuras, pues si la fianza civil se predica genéricamente del pago o cumplimiento de las obligaciones de un tercero, la LGP restringe el objeto del afianzamiento únicamente a las obligaciones «derivadas de operaciones de crédito» (art. 113).

Este es el sentido que interesa ahora subrayar: en virtud del aval la Administración Pública se obliga a pagar por un tercero las obligaciones derivadas de operaciones de crédito, en el caso de no hacerlo este. El elemento esencial, por tanto, es que con el afianzamiento la Administración expone los fondos públicos a las resultas de una obligación que no le correspondía asumir. De aquí que para su otorgamiento la LGP exija como regla general autorización por ley o, en determinados supuestos, autorización del Consejo de Ministros, previa declaración del interés público que lo motiva y fijación del importe máximo por la ley (arts. 114 y 115).

Por otra parte, la LGP no vincula la figura del aval a una determinada modalidad de actuación administrativa, con la sola excepción del supuesto contemplado en la letra b), apartado 2, del artículo 114, que

16 La LGP no emplea el término «fianza», sino "aval», aunque se remite expresamente a la regulación de la fianza en el CC. Sobre esta diferencia véase L. DíEz-PiCAzo (1993: 461-463). 
prevé la concesión de avales para financiar bienes e inversiones que deban revertir a la Administración General del Estado y hayan de quedar afectos a concesión administrativa, de obra pública o de colaboración público-privado. De aquí la versatilidad de la figura, que tradicionalmente sirvió como una técnica más de fomento y desde el inicio de la crisis se ha trasmutado en un instrumento para el rescate de la economía ${ }^{17}$.

Desde el punto de vista institucional, las administraciones públicas incluso constituyen entidades instrumentales especializadas en el afianzamiento de la actividad económica, como la Compañía Española de Reafianzamiento, de competencia estatal, o la entidad Avalmadrid, de ámbito autonómico ${ }^{18}$.

\section{B) Seguros}

Los seguros de caución constituyen en sentido estricto garantías ante el impago de las obligaciones del tomador, conforme dispone el artículo 68 de la Ley 50/1980, de 8 de octubre, de Contrato de Seguro $(\mathrm{LCS})^{19}$. No obstante, aquel contrato no resulta apropiado para la actividad de fomento de las exportaciones, donde la figura de la garantía del Estado tiene especial protagonismo ante los riesgos de las operaciones económicas en el extranjero, pues el tomador del seguro no podría ser la compañía exportadora española, sino el eventual incumplidor del pago, generalmente un operador extranjero.

De aquí que la mayor parte de las garantías que otorga la Administración como ayuda a la exportación se encaucen a través del seguro de crédito $^{20}$, por el que se obliga a indemnizar al asegurado las pérdidas que experimente a consecuencia de la insolvencia definitiva de sus deudores (art. 69 LCS). En este sentido, la vieja Ley 10/1970, de 4 de julio, por la que se modifica el régimen del Seguro de Crédito a la Exportación, prevé la cobertura por la Administración de los riesgos derivados del comercio exterior (art. primero), y la reciente Ley 8/2014, de 22 de abril, sobre cobertura por cuenta del Estado de los riesgos de la internacionalización de la economía española, amplía la cobertura del Estado frente a otros riesgos

17 Las leyes de presupuestos generales acostumbraban a incluir una autorización anual de avales como técnica de fomento, con el objeto de mejorar la financiación de la actividad productiva empresarial (e.g. Ley 39/2010, arts. 49 y 50).

18 Ambas bajo la Ley 1/1994, de 11 de marzo, sobre el régimen jurídico de las sociedades de garantía recíproca.

19 L. Díez-Picazo (1993: 465 y ss.) y Á. Carrasco Perera et al. (2015: 589 y ss.).

20 M. SALVAdOR ARMendÁRIz (2009), La cobertura pública en el seguro de crédito a la exportación en España: cuestiones jurídico-públicas, Madrid: Instituto de Ciencias del Seguro. 
más genéricos de impago de las exportaciones e inversiones en el exterior (art. 2). La asunción de los riesgos puede corresponder a la Compañía Española de Seguros de Crédito a la Exportación, a agentes gestores contratados por la Administración o al Consorcio de Compensación de Seguros.

\section{C) Fondo de Garantía Salarial}

En el ámbito de las relaciones laborales, debe destacarse la relevante función que el Estatuto de los Trabajadores encomienda al Fondo de Garantía Salarial. Legalmente, este organismo autónomo adscrito al Ministerio de Empleo y Seguridad Social deberá asumir el pago a los trabajadores del importe de los salarios pendientes de pago a causa de insolvencia o concurso del empresario, así como subrogarse en los derechos y acciones que correspondieran a los trabajadores indemnizados (art. 33 del Estatuto de los Trabajadores).

\section{D) Garantías en el sector financiero}

En el sector financiero, debe consignarse la función de garantía que el Estatuto Legal del Consorcio de Compensación de Seguros (Real Decreto Legislativo 7/2004, de 29 de octubre) atribuye a esta entidad pública empresarial adscrita al Ministerio de Economía y Competitividad. Dentro de su actividad de aseguramiento interesa destacar las garantías que asume respecto de las obligaciones de terceros, como son las derivadas de riesgos extraordinarios ocasionados por el terrorismo, sedición, etc.; riesgos nucleares; o responsabilidad civil en la circulación de vehículos a motor de suscripción obligatoria [arts. 6.1, b) y 9].

Entre las garantías del Estado, en principio no cabría incluir las que otorgan el Fondo de Garantía de Depósitos ${ }^{21}$ y el Fondo de Garantía de Inversiones $^{22}$, pues la naturaleza jurídica de los fondos es la de corporaciones de derecho público - aun cuando sus normas reguladoras no les otorguen tal calificación jurídica-, de suerte que la carga económica derivada de las garantías corresponde a las entidades financieras adheridas a los fondos y no a la Administración Pública. No obstante, en epígrafes posteriores habremos de volver sobre esta garantía ya que plantea algunos interrogantes acerca de su responsable último.

21 Real Decreto-ley 16/2011, de 14 de octubre, por el que se crea el Fondo de Garantía de Depósitos de Entidades de Crédito.

22 Artículos 198 y ss. de la Ley del Mercado de Valores (Real Decreto Legislativo 4/2015, de 23 de octubre). 


\section{E) La mal llamada responsabilidad patrimonial}

La llamada «responsabilidad patrimonial de la Administración» en la concesión de obra pública ha operado en la práctica como un sistema de garantía de la Administración respecto de las obligaciones asumidas por el concesionario frente a las entidades financieras acreedoras. Convendrá recordar que el régimen establecido en la primera redacción del artículo 271 de la Ley de Contratos del Sector Público (LCSP) no configuraba un régimen de responsabilidad patrimonial - pese a que se haya extendido esta denominación-, como tampoco establecía expresamente un régimen de garantía de la Administración, sino un sistema de reembolso de las inversiones y justiprecios expropiatorios que hubiera asumido el concesionario para el caso de resolución de la concesión. No obstante, en la práctica estos derechos de reembolso se emplearon por los concesionarios como garantía de las obligaciones asumidas por ellos frente a las entidades financiadoras de la concesión. De suerte que la Administración contratante quedó en la posición de garante de aquellas obligaciones frente a los acreedores del concesionario en caso de resolución.

Sin que sea preciso extender aquí la exposición de vicisitudes ya conocidas, en el caso de ciertas autopistas de peaje la escasa rentabilidad de las concesiones, unida a los elevados justiprecios que las concesionarias hubieron de atender, condujo a estas últimas a una situación de insolvencia. Tanto la Administración como el legislador han adoptado distintas medidas para tratar de evitar los desembolsos, pero aquí interesa fundamentalmente la reforma introducida en la LCSP por la Ley 40/2015, de 1 de octubre, de Régimen Jurídico del Sector Público (disposición final novena), que limita sensiblemente el alcance de los reembolsos en los supuestos de resolución de la concesión por causas no imputables a la Administración, como, por ejemplo, por insolvencia del concesionario (art. 271); así como añade un apartado 4 al artículo 254, que regula, esta vez sí, de manera específica el otorgamiento de garantías a la financiación del concesionario.

\section{F) Garantías al alquiler}

Finalmente, debe dejarse constancia del sistema de garantías públicas frente a los impagos de los inquilinos como medida de fomento del arrendamiento de viviendas. Sirva como muestra el caso de la extinta Sociedad Pública de Alquiler (SPA), que «garantiza al propietario que a partir de la firma del primer contrato, y mientras la vivienda perma- 
nezca en esta bolsa, percibirá esta renta independientemente de que la vivienda esté o no ocupada» ${ }^{23}$. No obstante, en el modelo de "Contrato de intermediación y de gestión de vivienda para su arrendamiento» elaborado por el entonces Ministerio de Vivienda y la SPA, esta última únicamente se comprometía con el propietario al "pago de una cuota mensual, mientras esté ocupada su vivienda» (cláusulas primera y segunda). Esto es, otorgaba una garantía del pago estipulado para el caso de incumplimiento por el arrendatario.

\section{LA GARANTÍA DEL ESTADO EN EL DERECHO DE EMERGENCIA ECONÓMICA}

Si la tipología que acaba de exponerse describe la actuación garante de la Administración Pública en España en un contexto de normalidad económica, la crisis desatada en 2007 ha dado lugar a la aprobación de un derecho de emergencia económica, que ha colocado a los poderes públicos en la posición de garantes últimos del funcionamiento de la economía.

Aun dentro de este derecho pueden diferenciarse dos fases en la actuación garante de los poderes públicos. En un primer estadio la recesión afectó principalmente a la sociedad, sembrando la desconfianza sobre la capacidad de las empresas para responder de sus obligaciones pecuniarias. Por lo que el sector privado buscó la mayor solvencia del Estado para que respaldase su cuestionada capacidad de pago y así conseguir financiación de terceros. En este contexto, los poderes públicos articularon operaciones de rescate mediante avales públicos -y otras medidas que aquí no se analizan - por las que garantizaron el cumplimiento de las obligaciones de los sectores que consideraron estratégicos para el funcionamiento de la economía, como la banca ${ }^{24}$, el automóvil ${ }^{25}$ o la electricidad ${ }^{26}$. Otro tanto ocurrió en el ámbito auto-

23 Acuerdo del Consejo de Ministros de 8 de abril de 2005.

24 El artículo 1 del Real Decreto Ley 7/2008, de 13 de octubre, de Medidas Urgentes en Materia Económico-Financiera en relación con el Plan de Acción Concertada de los Países de la Zona Euro, autorizó avales en favor de la banca hasta un importe de 100000 millones de euros.

El Real Decreto Ley 4/2009, de 29 de marzo, por el que se autoriza la concesión de garantías derivadas de la financiación que pueda otorgar el Banco de España a favor de la Caja de Ahorros de Castilla-La Mancha.

El Real Decreto Ley 9/2009, de 26 de junio, sobre reestructuración bancaria y reforzamiento de los recursos propios de las entidades de crédito, autorizó el otorgamiento de avales en favor del FROB por importe de 27000 millones de euros (disposición final segunda).

25 La Ley 26/2009, de 23 de diciembre, de Presupuestos Generales del Estado para el año 2010, autorizó avales para el sector automovilístico por importe de hasta 1000 millones de euros (art. 54, tres).

26 El Real Decreto Ley 6/2009, de 30 de abril, por el que se adoptan determinadas medidas en el sector energético y se aprueba el bono social, autorizó el otorgamiento de avales para afrontar el déficit de tarifa por importe de hasta 10000 millones de euros (art. 1.8). 
nómico respecto de los sectores regionales considerados prioritarios ${ }^{27}$. Muchas de las autorizaciones para el otorgamiento de avales fueron renovándose e incrementándose anualmente en tanto persistió la desconfianza en los mercados, mientras que en el resto de los sectores económicos que no se beneficiaron de los avales públicos se multiplicaron las situaciones concursales, lo que determinó que el Estado tuviera que hacer frente a las garantías por salarios impagados ${ }^{28}$.

En el segundo estadio de la crisis, su prolongación y los esfuerzos públicos por apoyar a la economía terminaron por socavar también la confianza en la solvencia de diversos Estados y sus entidades territoriales. En el caso español, el Estado también hubo de otorgar su aval para rescatar a determinadas entidades locales españolas, así como a otros Estados de la UE. Paradójicamente, el propio Estado también acabó viendo seriamente cuestionada su reputación patrimonial - justificación última de la actuación garante- y, a su vez, hubo de ser rescatado precisamente mediante la utilización de avales otorgados por otros Estados que, en su conjunto, inspiraban mayor confianza económica.

En el ámbito interno, el primer plan de rescate se articuló mediante un Acuerdo de la Comisión Delegada del Gobierno para Asuntos Económicos, que instruyó al Instituto de Crédito Oficial para la puesta en funcionamiento de una línea de avales que garantizara los impagos de facturas endosadas por las empresas y autónomos correspondientes a obras y servicios prestados a entidades locales ${ }^{29}$.

En el plano de las relaciones internacionales, el Acuerdo Marco de la Facilidad Europea de Estabilización Financiera (FEEF) ejemplifica la situación paradójica del Estado. Este Acuerdo contemplaba que la FEEF fuera respaldada por avales irrevocables de los Estados miembros de la zona euro con el propósito de obtener financiación hasta un importe de 440000 millones de euros con los que rescatar a los Estados miembros en dificultades. En la función de garante que aquí se analiza, España suscribió el citado Acuerdo, convirtiéndose así en avalista de las obligaciones de otros Estados en dificultades (BOE 11.VII.2011). Pero en 2012 fue precisamente España la que recibió de la FEEF el rescate para la reestructuración de su sistema financiero (Memorando ya citado).

27 Por todos, capítulo II de la Ley Foral 18/2008, de 6 de noviembre, de medidas para la reactivación de la economía de Navarra 2009-2011.

28 Los pagos anuales del FOGASA por los salarios garantizados se situaron al comienzo de la crisis, 2007, en el entorno de los 380 millones de euros, pero ante el incremento de situaciones concursales, año tras año aumentó fuertemente el volumen de pagos, hasta superar en 2014 los 2288 millones de euros (http://www.empleo.gob.es/fogasa/estadisticas15.html).

29 Preámbulo del Real Decreto Ley 5/2009, de 24 de abril, de medidas extraordinarias y urgentes para facilitar a las entidades locales el saneamiento de deudas pendientes de pago con empresas y autónomos. 
Contemplado en su conjunto, este escalonamiento de garantías otorgadas para afrontar la crisis ha terminado por establecer una comunicación patrimonial indirecta que surge de los deudores españoles y se eleva hasta los contribuyentes de otros Estados miembros. Así se aprecia especialmente en el caso de la Sociedad de Gestión de Activos Procedentes de la Reestructuración Bancaria, S.A. (Sareb, conocida como «banco malo»). Se trata de una entidad a la que el Estado otorgó avales por 55.000 millones de euros para que pudiera adquirir inmuebles y préstamos inmobiliarios de entidades financieras en dificultades ${ }^{30}$. De tal modo que el crédito bancario otorgado a un particular para la adquisición de una vivienda ha acabado transferido a la Sareb merced al aval otorgado por el Estado. A su vez, el Estado ha podido rescatar su sistema bancario merced a la financiación obtenida de la FAAF, que ha recibido el aval de los Estados miembros de la zona euro, cuya reputación de solvencia descansa esencialmente en la contribución de sus ciudadanos a los respectivos sistemas tributarios.

\section{Problemática jurídica de la actuación garante del Estado}

Una situación económica tan excepcional como la vivida en los últimos años, que ha requerido la adopción de medidas extraordinarias, se ha afrontado con una regulación de las garantías públicas concebida bajo la premisa de la normalidad económica, donde el Estado apenas debía tener protagonismo como garante de las obligaciones ajenas. Este desajuste entre el régimen jurídico y la actuación reciente del Estado ha generado una problemática, cuyas manifestaciones más relevantes interesa ahora analizar.

1. Consideración de las garantías públicas como recursos escasos de la Administración

La intensidad con la que el Estado ha empleado los avales y garantías en general plantea un primer problema derivado de la insuficiente regulación jurídica de la materia. En particular, la regulación específica sobre los avales públicos se encuentra en la LGP (arts. 113 a 118) y,

30 Fue creada por la disposición adicional séptima de la Ley 9/2012, de 14 de noviembre, de reestructuración y resolución de entidades de crédito, como exigencia del rescate a España (Memorando de 2012, apartado IV, 21 y 22). El aval fue autorizado por la Ley 2/2012, de 29 de junio, de Presupuestos Generales del Estado para el año 2012 [art. 52, dos, e)]. 
supletoriamente, en las correspondientes normas de derecho privado ${ }^{31}$. Sin embargo, estas normas tan solo contienen un tratamiento parcial de la figura y dejan fuera de su regulación aspectos esenciales para el derecho administrativo.

Si centramos la atención en los avales, se advierte que su regulación en la LGP es propiamente hacendística, pues atiende esencialmente a su posible incidencia sobre las finanzas públicas, a la competencia para su otorgamiento, así como a los instrumentos jurídicos necesarios para autorizarlos. Estas cuestiones son coherentes con el planteamiento general de la norma, cuyo objeto es la gestión presupuestaria, y no las relaciones jurídicas que se entablan entre la Administración y los ciudadanos, cuyo tratamiento corresponde supletoriamente al derecho privado (art. 4.3). Ahora bien, el CC parte del principio de la autonomía de la voluntad, por lo que únicamente se ocupa de las posiciones jurídicas en que quedan las partes una vez se ha celebrado el negocio jurídico.

De manera que la regulación vigente en materia de avales públicos excluye de su objeto la formación de la voluntad de la Administración Pública en los aspectos que no sean puramente hacendísticos. En concreto, la materia propia del derecho administrativo queda en buena medida desatendida, pues nada se dice sobre las técnicas para hacer efectivo el principio de igualdad de los ciudadanos en el acceso a un recurso escaso como los avales públicos ${ }^{32}$, necesidad de fundamentar la elección del sector de la economía que se vaya a garantizar frente a los demás, procedimiento de tramitación, convocatoria pública o criterios de selección de los beneficiarios. La falta de regulación se pone también de manifiesto cuando la LGP remite el tratamiento de las ayudas o subvenciones a su normativa específica [art. 4.2, f)], pues, a pesar de este mandato, el derecho español únicamente regula de manera específica las subvenciones, pero no otras ayudas como las garantías públicas ${ }^{33}$.

En un plano dogmático las carencias de aquella regulación positiva deberían ser integradas con los principios del derecho administrativo. Concretamente la LCSP condensa en sus disposiciones los principios para la gestión de recursos escasos (art. 4.2). Sin embargo, más allá de su

31 En el caso de la fianza, artículos 1822 y ss. del CC y, para las garantías financieras, el Real Decreto Ley 5/2005, de 11 de marzo, de Reformas Urgentes para el Impulso a la Productividad y para la Mejora de la Contratación Pública. ss.).

32 M. SÁnchez Morón (2015), Derecho administrativo, Madrid: Tecnos (págs. 812 y 815 y

33 Sobre la consideración de las garantías como ayudas de Estado, véanse la Comunicación de la Comisión relativa a la aplicación de los artículos 87 y 88 del Tratado CE a las ayudas estatales otorgadas en forma de garantía (2008/C 155/02) y la STJUE de 5 de marzo de 2015, Estado português, C-667/13, apartado 52. 
función informadora y de control, en la práctica no es posible administrar solo con principios, que siempre resultan de difícil identificación y de más compleja aplicación al caso concreto ${ }^{34}$, ante la falta de reglas que concreten un ámbito de aplicación, umbrales, plazos, trámites y las restantes precisiones de detalle que permiten dirigir la actuación administrativa ${ }^{35}$.

La crisis muestra la importancia de que el derecho garantice la igualdad de los operadores en el acceso a los recursos públicos escasos, pues, al margen del análisis de la compatibilidad con el mercado de estas ayudas (art. 113.2 LGP) ${ }^{36}$, las regulaciones dictadas con carácter singular para cada categoría de avales no permiten acreditar las excepcionales circunstancias por las que solo determinados sectores económicos fueron considerados estratégicos y se pudieron beneficiar de las garantías públicas, mientras que en el resto se multiplicaron exponencialmente las insolvencias ${ }^{37}$.

Por tales razones, la vertiente hacendística de la LGP requiere ser completada con la consideración de que las garantías públicas también precisan de unas reglas específicas para la gestión de estos recursos escasos por la Administración Pública, singularmente para salvaguardar la igualdad de derechos ${ }^{38}$. Es de recordar que la regulación de las subvenciones se justifica precisamente en que las reglas generales del procedimiento no satisfacían esta necesidad ${ }^{39}$.

Por último, conviene notar que, aun cuando la ley deba autorizar la cuantía máxima de las garantías públicas, se concilia mejor con el

34 Sobre la eficacia jurídica de los principios véanse L. PRIETO SANCHís (1992), Sobre principios y normas, Madrid: CEC (págs. 56 y ss.) y M. BELAdIEz Rojo (1994), Los principios jurídicos, Madrid: Tecnos (págs. 83 y ss. y 94 y ss.).

35 C. Chinchilla (2016), «El derecho de la Unión Europea como freno a la huida del derecho administrativo», en Revista de Administración Pública, 200, págs. 361-383 (págs. 364-367).

36 Durante la crisis la Comisión Europea ha flexibilizado notablemente el reconocimiento de compatibilidad de las ayudas de Estado, incluidos los avales: G. FERNÁNDEZ Farreres (2012), «Subvenciones y ayudas económicas en tiempos de crisis», en Revista Española de Derecho Administrativo, 154, págs. 19-48 (págs. 26-30); M. FeHLING (2010), «La reacción de los Estados europeos frente a la crisis y el Derecho europeo de ayudas públicas», en El Cronista del Estado Social y Democrático de Derecho, 11, págs. 6-13; y A. EstoA Pérez (2010), «Ayudas de Estado y crisis actual: orientaciones de la Comisión y ayudas al sector financiero español», en Revista Española de Derecho Europeo, 34, págs. 265-300.

37 Sirvan como muestra las Órdenes ministeriales: PRE/1516/2010, de 8 de junio; PRE/2986/2008, de 14 de octubre y EHA/3364/2008, de 21 de noviembre, sobre procedimiento para el otorgamiento de avales en el ramo del automóvil, la flota mercante o las entidades de crédito, respectivamente.

38 L. ArRoyo (2015), «Las bases constitucionales de la actividad administrativa de adjudicación de derechos limitados en número», en L. Arroyo y D. Utrilla (eds.), La administración de la escasez, Madrid: Marcial Pons (págs. 47-107).

39 Sobre la validez de un procedimiento general en una materia especializada, como la subvencional, véase la Sentencia constitucional 130/2013, de 4 de junio (f. j. 9), en la que precisamente se diferencia la vertiente hacendística de las subvenciones respecto de los aspectos procedimentales. 
respeto del principio de igualdad si no determina también los sectores que hayan de beneficiarse de aquellas. Ya que, frente a la ley singular ${ }^{40}$, el reconocimiento de la discrecionalidad administrativa en este punto permite someter la decisión a las reglas del procedimiento, así como al control jurisdiccional ordinario de las razones en que se funda.

\section{La incertidumbre como premisa del aval}

La utilización de los avales públicos durante la crisis ha puesto de relieve un elemento caracterizador de su naturaleza jurídica que en el ámbito privado suele pasar inadvertido. Se trata de la incertidumbre respecto del incumplimiento de las obligaciones afianzadas en el momento del otorgamiento del aval.

Las obras de derecho privado no destacan la incertidumbre como uno de los elementos que caracterizan las fianzas, seguramente porque su presencia resulta evidente y porque en el tráfico privado no se garantiza una obligación cuyo incumplimiento ya consta al fiador. Pero sin lugar a dudas se deduce de la propia redacción del artículo 1822 del CC: «Por la fianza se obliga uno a pagar o cumplir por un tercero, en el caso de no hacerlo éste». Es precisamente la incertidumbre la que hace contingente la obligación de pago.

De otorgarse la fianza con conocimiento de que la obligación había sido previamente incumplida no habría una transferencia de riesgos, pues el fiador no se comprometería para el caso de que no cumpliera el deudor, sino que simplemente se comprometería «una vez ha incumplido el deudor». Tampoco estaríamos en un supuesto de una simple asunción cumulativa de deuda ajena, en la que un tercero asume directamente la deuda (no vencida) del obligado ${ }^{41}$, pues a falta de incertidumbre el fiador en realidad asumiría la obligación «vencida e incumplida». En definitiva, si la obligación ya ha sido incumplida, el fiador se coloca en la posición de codeudor y también en inmediato requerido para el pago.

También la cuantía de la retribución por el otorgamiento del aval es reveladora de la incertidumbre, pues generalmente consiste en una comisión muy inferior al importe garantizado (art. 117 LGP). En efecto, carecería de sentido económico el cobro de una pequeña comisión si el fiador sabe anticipadamente que asumirá el importe total de la obligación impagada.

40 J. M. Díaz Lema (2013), «El fin del privilegio de la ley singular: comentario a la STC 129/2013, de 4 de junio», en El Cronista del Estado Social y Democrático de Derecho, 39 (págs. 62-73).

41 Á. Carrasco Perera et al. (2015: 166). 
Trasladadas estas ideas al derecho administrativo, debe dilucidarse si la Administración puede otorgar avales sin incertidumbre. Esta cuestión se plantea ahora porque durante la crisis la Administración se ha servido de los avales públicos para garantizar obligaciones ya vencidas e incumplidas. En concreto, en 2009 el Estado salió al rescate de numerosas entidades locales y sus proveedores - ambos se beneficiaron de la medida-mediante el otorgamiento de una línea de avales "para facilitar a las Entidades Locales el saneamiento de deudas pendientes de pago con empresas y autónomos». Como exponía el Real Decreto Ley 5/2009, de 24 de abril: «La evolución de la situación económica y su impacto en la economía española están ocasionando retrasos en el pago de las obligaciones contraídas por las Entidades Locales, con el consiguiente efecto negativo sobre la liquidez de las empresas, en especial las pequeñas y medianas y los autónomos» y para hacer frente a aquella situación, la norma anunciaba que, entre otras medidas, la «Comisión Delegada del Gobierno para Asuntos Económicos ha instruido al Instituto de Crédito Oficial para la inmediata puesta en funcionamiento de una línea de avales que garantice los impagos de facturas endosadas por las empresas y autónomos correspondientes a obras y servicios prestados a Entidades Locales» ${ }^{42}$. Esto es, el Estado se hizo garante de numerosas deudas de las entidades locales a sabiendas de que estas estaban incurriendo en mora. Faltaba, por tanto, el elemento de la incertidumbre, a pesar de lo cual se otorgaron los correspondientes avales.

Este tipo de garantías públicas resulta problemático, no solo por la falta de la incertidumbre acerca del pago por el obligado en la figura del aval —lo que por sí sola cuestiona su validez-, sino principalmente por razones presupuestarias. En este sentido, debe tenerse presente que cuando la ley autoriza el otorgamiento de avales hasta un determinado importe no habilita a la Administración para que contraiga de manera directa una obligación pecuniaria de un tercero, sino únicamente para que aquella se coloque en la posición de garante para el caso de que aquella obligación llegara a incumplirse. La diferencia es importante, pues la razón por la que las leyes de presupuestos pueden autorizar el otorgamiento de avales en cuantías que multiplican la capacidad de pago de la Administración es precisamente porque existe un elemento de incertidumbre acerca de si la Administración habrá de asumir finalmente el pago garantizado, y porque se confía en que solo será ejecutada una mínima parte de todos los avales concedidos. Que la LGP opera con este elemento de incertidumbre se acredita en el artículo 118, en el que se habilita a la Administración para establecer mecanismos para limitar

\footnotetext{
42 Acuerdo de 23 de abril de 2009.
} 
el riesgo de ejecución de los avales otorgados. Este precepto carecería de sentido si se conociera anticipadamente el incumplimiento de la obligación, pues no existiría riesgo, sino certeza del impago.

Por tanto, cabe plantearse si los avales prestados sobre deudas ya impagadas responden a la figura de los avales previstos en la LGP o si, más bien, constituyen garantías públicas de nueva factura, por las que se otorga un refuerzo al acreedor, pero la Administración asume directamente la posición de deudora pecuniaria. De admitirse en nuestro derecho tales garantías sin incertidumbre, lo lógico sería que se diferenciaran de los avales, ya que al perder su carácter contingente exigirán la correspondiente dotación presupuestaria de fondos para atender la deuda contraída. Como también sería necesario reforzar las exigencias de motivación para la asunción de una carga tan onerosa.

3. El principio de legalidad ante el otorgamiento de garantías implícitas, informales o de importe indeterminado

Se analizan ahora distintos supuestos en que la Administración o sus entidades dependientes otorgan garantías implícitas, informales o sin límite autorizado presupuestariamente, de manera que se separan del régimen general de los avales previsto en la LGP.

El primero de los supuestos es el de las garantías implícitas, esto es, cuando la Administración no avala expresamente la obligación de un tercero, pero jurídicamente se coloca en la posición de garante frente a los ciudadanos. En concreto, la cuestión se plantea a raíz de que el Gobierno elevase la cuantía garantizada de los depósitos en entidades de crédito ${ }^{43}$. De acuerdo con la redacción entonces vigente del Real Decreto 2606/1996, de 20 de diciembre, sobre fondos de garantía de depósitos de entidades de crédito, se reconocía a los depositantes una garantía de hasta 20000 euros (art. 7). Como ya se ha anticipado, este sistema respondía al modelo de las corporaciones de derecho público: las entidades de crédito debían pertenecer obligatoriamente al fondo, aportar anualmente el 2 por 1000 de los depósitos garantizados y si el patrimonio de un fondo alcanzaba una cuantía suficiente para el cumplimiento de sus fines (art. 3), por orden ministerial podían minorarse las aportaciones, como efectivamente ocurrió respecto de la banca, que se redujeron a la mitad ${ }^{44}$.

\footnotetext{
43 La garantía también comprendía a los inversores del mercado de valores, pero por razones de claridad expositiva únicamente se toma como ejemplo la garantía a los depósitos.

44 Orden de 12 de febrero de 1997 por la que se reducen las aportaciones al Fondo de Garantía de Depósitos en establecimientos bancarios.
} 
Durante la crisis prendió la desconfianza sobre la capacidad de las entidades de crédito de reembolsar los depósitos, por lo que el Gobierno adoptó el Real Decreto 1642/2008, de 10 de octubre, cuyo artículo único elevaba el importe garantizado hasta los 100000 euros $^{45}$. Ahora bien, ante las dificultades económicas que atravesaban las entidades de crédito no se incrementó la aportación al fondo, a pesar de que el patrimonio de los fondos no alcanzaba para atender unas garantías cuyo importe se había multiplicado por cinco.

Jurídicamente debe descartarse que existiera formalmente un aval público, pues su otorgamiento no se presume (art. 1827 CC) y, en todo caso, habría requerido una autorización por ley (art. 114 LGP). Pero sabemos que el concepto de garantía es más amplio e incluye todo instrumento jurídico que asegura el cumplimiento de una obligación. En este caso, ciertamente existía una garantía, pues el Real Decreto otorgaba a los depositantes un derecho subjetivo consistente en disfrutar de cobertura por la nueva cuantía. Ahora bien, dada la situación económica extrema, ni los fondos ni las entidades de crédito tenían capacidad para asumir compromisos por tan elevados importes, como se comprobó posteriormente durante la reestructuración bancaria. De manera que cabe considerar si la Administración habría quedado implícitamente en la posición de garante de haberse producido el impago de depósitos por la parte que no pudieran cubrir los fondos. Abonan esta interpretación las circunstancias de que, en otro caso, la cobertura habría quedado parcialmente vacía de contenido; que la decisión de constituir una garantía tan elevada fue del Consejo de Ministros; y, finalmente, que superaba ampliamente las exigencias de la Directiva e incluso del ECOFIN. De existir la garantía implícita de la Administración, como aquí se defiende, esta se habría otorgado sin autorización presupuestaria y por un importe potencial completamente indeterminado.

Un supuesto distinto, el de garantía informal, se da en el caso de la Sociedad Pública de Alquiler, que garantizaba al propietario la percepción de una renta mientras estuviera ocupada la vivienda, incluso ante el impago del inquilino (véase supra). En este caso el compromiso reunía todas las características ya analizadas de una garantía pública, a pesar de que se otorgaba dentro de un contrato privado de gestión del alquiler, por el representante de una sociedad del sector público y sin que constase autorización presupuestaria sobre los compromisos.

Tanto las garantías implícitas, como las informales o las que puedan suponer compromisos por un importe potencial indeterminado ponen

45 La Directiva 94/19/CE de 30 de mayo, fijaba entonces la garantía en 20000 euros y el ECOFIN (7.X.2010) acordó elevar el umbral mínimo en 50000 euros.

Revista de Administración Pública

ISSN-L: 0034-7639, núm. 201, Madrid, septiembre-diciembre (2016), págs. 101-129

http://dx.doi.org/10.18042/cepc/rap.201.04 
nuevamente de manifiesto la necesidad de revisar la regulación de las garantías públicas. Pues la posibilidad de que el sector público asuma compromisos contingentes de pago, como consecuencia de garantías implícitas o informales, es difícilmente compatible con el principio de legalidad presupuestaria, conforme al cual la Administración solo podrá contraer obligaciones financieras de acuerdo con las leyes (art. 131.4 CE) y las obligaciones de la Hacienda pública solo son exigibles cuando resulten de la ejecución de los presupuestos, de conformidad con lo dispuesto en la LGP, de sentencia judicial firme o de operaciones no presupuestarias legalmente autorizadas (art. 21 LGP).

\section{El principio constitucional de sostenibilidad económica como límite a la garantía del Estado}

A la vista de la magnitud extraordinaria que han alcanzado las garantías comprometidas por el Estado durante la crisis cabe preguntarse si el principio constitucional de sostenibilidad económica impone restricciones a la actuación garante de la Administración más allá de la regulación positiva de los avales públicos contenida en la LGP. En torno a esta idea no está de más recordar que el colapso de las finanzas públicas de Irlanda se debió precisamente al otorgamiento de avales a su sistema bancario por encima de su capacidad presupuestaria.

El principio de sostenibilidad fue primero desarrollado en materia medioambiental (Informe Brundtland, 1987), bajo la idea de que la actuación humana se pueda mantener durante largo tiempo sin agotar los recursos $(\mathrm{RAE})^{46}$. Con este significado nuclear la idea fue luego tomada en la regulación económica ${ }^{47}$, e introducida como principio en la reforma constitucional del artículo 135, donde aparece enunciado de manera indirecta en el apartado 4, y se cuenta entre los principios que la Constitución dispone sean desarrollados por ley orgánica. Esta referencia ancilar a él no ha impedido que haya irrumpido con fuerza en la ordenación de las finanzas públicas, como ponen de relieve los títulos

\footnotetext{
${ }^{46}$ Sobre este principio y su recepción en el derecho español: T.-R. FERnÁNDEZ (2016), «Reflexiones sobre la sostenibilidad de los servicios públicos, un nuevo principio general en gestación», en Revista de Administración Pública, 200, págs. 439-450 y C. CHinchilla (2016: 372 y ss.).

${ }^{47}$ Véase el art. 2 de la Ley 2/2011, de 4 de marzo, de Economía Sostenible, y el art. 8 de la Ley 27/2011, de 1 de agosto, sobre actualización, adecuación y modernización del sistema de Seguridad Social, que introduce en el derecho español el llamado «factor de sostenibilidad». En el derecho alemán ha tenido especial predicamento en cuanto solidez futura de las finanzas públicas: W. KaHL (2011), Nachhaltige Finanzstrukturen im Bundesstaat, Tübingen: Mohr Siebeck.
} 
de la Ley Orgánica 2/2012, de 27 de abril, de Estabilidad Presupuestaria y Sostenibilidad Financiera, y la Ley 23/2013, de 23 de diciembre, reguladora del Factor de Sostenibilidad y del Índice de Revalorización del Sistema de Pensiones de la Seguridad Social.

La Ley Orgánica 2/2012 define la sostenibilidad como la capacidad para financiar compromisos de gasto presentes y futuros dentro de los límites de déficit, deuda pública y morosidad de deuda comercial (art. 4). En esto se diferencia de la estabilidad presupuestaria, pues la sostenibilidad no se vincula tan directamente con la situación presupuestaria actual como se proyecta al futuro, tratando de impedir que las administraciones públicas asuman compromisos económicos que no vayan a ser capaces de atender. Precisamente el carácter prospectivo de la sostenibilidad dificulta su aplicación y, sobre todo, el control sobre su ejercicio, ya que necesariamente ha de basarse en previsiones de escenarios inciertos a partir de datos actuales incompletos.

En todo caso, así entendido el nuevo principio constitucional, las garantías públicas son un campo abonado para su aplicación, dado que aquellas incorporan precisamente potenciales compromisos futuros de gasto que pueden desembocar en graves desequilibrios presupuestarios. Ciertamente, el principio de sostenibilidad económica únicamente es aplicable a partir de la entrada en vigor de la reforma constitucional de 2011, pero debe tenerse en cuenta que fue al año siguiente cuando el Estado empleó con mayor intensidad la técnica de los avales en diversos rescates económicos. De esta manera, aun cuando la LGP no lo haya incorporado a sus disposiciones, este principio habrá de integrarse entre los límites a la capacidad de garantía de la Administración, especialmente en aspectos como la ponderación de los riesgos, su justificación estadística o el montante acumulado de las garantías, hasta ahora escasamente atendidos (art. 118).

Como reflexión final puede apuntarse que los audaces rescates acometidos por el Estado durante la crisis económica han puesto a prueba la regulación de las garantías públicas en nuestro derecho. Normativa que, a la vista de la problemática expuesta, reclama una revisión en profundidad para adecuarla a la mayor intensidad de su utilización, a las exigencias derivadas de su naturaleza como recurso público escaso, a la evidencia de que la figura del aval no agota el elenco de las posibles garantías que puede otorgar el Estado, para poner freno a su utilización implícita o informal, así como para conciliarla con el principio constitucional de sostenibilidad económica. 


\section{INCIDENCIA DE LAS GARANTÍAS PÚBLICAS SOBRE LA RELACIÓN ESTADO- SOCIEDAD}

La actuación garante del Estado descrita es producto de un derecho de emergencia económica y, por lo mismo, deseablemente transitorio. No obstante, sus efectos parecen llamados a dejar una huella visible sobre el derecho positivo, por lo que a continuación se analiza la incidencia que la garantía del Estado está teniendo en el fortalecimiento de sus potestades de intervención, así como en el entendimiento de la economía de mercado.

\section{Los rescates públicos como modernos títulos de intervención}

El efecto más visible de la garantía del Estado sobre la economía es el fortalecimiento de sus potestades de intervención en las instituciones y sectores rescatados. El fenómeno presenta dos manifestaciones difícilmente escindibles. La primera de ellas se refiere al otorgamiento de garantías en sentido estricto, tal y como han sido estudiadas en las páginas precedentes, normalmente mediante el otorgamiento de avales. Pero las garantías no se pueden disociar de la finalidad con la que se han empleado, que ha sido el rescate de sectores enteros de la economía, así como de entidades públicas territoriales e incluso de algunos Estados, por lo que interesa detenerse ahora en esta segunda manifestación del fenómeno.

En efecto, a consecuencia de la intensidad de la crisis los poderes públicos se han visto compelidos a ejecutar rescates, no solo mediante el otorgamiento de garantías, sino muy frecuentemente mediante la inyección de fondos públicos. Sin ánimo exhaustivo, además de los citados, cabe recordar que en España se creó el FROB como mecanismo de rescate bancario ${ }^{48}$, el Banco Central Europeo (BCE) ha inyectado ingentes cantidades de liquidez en las entidades financieras ${ }^{49}$ y, en fin, el Estado ha arbitrado sucesivos fondos de liquidez autonómica y local ${ }^{50}$. Al final del proceso, sea mediante avales o con inyección de fondos públicos, el

\footnotetext{
48 M. SAlVAdOR ARMENdáRIZ (2014), «El nuevo modelo de regulación bancaria y su encaje constitucional», en M. SALVAdOR ARMENDÁRIZ (dir.), Regulación bancaria: transformaciones y Estado de Derecho (págs. 33-130), Cizur Menor: Aranzadi (págs. 98 y ss.).

49 Decisión del Banco Central Europeo de 14 de diciembre de 2011, sobre medidas temporales adicionales relativas a las operaciones de financiación del Eurosistema y la admisibilidad de los activos de garantía (BCE/2011/25).

50 Real Decreto Ley 17/2014, de 26 de diciembre, de medidas de sostenibilidad financiera de las comunidades autónomas y entidades locales y otras de carácter económico.
} 
Estado ha asumido o proporcionado fondos para atender obligaciones de pago que habían contraído sujetos privados o entidades públicas territoriales.

Conviene precisar que estas intervenciones masivas del Estado sobre la economía no han respondido a unos planteamientos ideológicos previos, sino que se han impuesto como resultado necesario por el funcionamiento de las economías modernas, como acredita la circunstancia de que hayan tenido lugar desde Estados Unidos, pasando por Europa y hasta Asia, cualquiera que haya sido el signo político de los responsables en cada momento.

Esta actuación muestra que en caso de extrema necesidad, los poderes públicos no tienen otra alternativa que rescatar las instituciones y sectores estratégicos, generando de esta manera una suerte de "garantía latente» del Estado. No son garantías en sentido propio, no existe obligación alguna (arts. 1089 y 1090 CC), y las autoridades deciden discrecionalmente cuándo una determinada institución debe ser rescatada por razón de su carácter sistémico para el buen funcionamiento de la economía ${ }^{51}$. Pero lo cierto es que en el plano europeo, conforme vaticinó SCHUMAN $^{52}$, el avance incesante en la integración ha producido una trabazón de intereses tan intensa que la UE difícilmente puede permitirse la insolvencia de uno de sus miembros. Mientras que en las economías nacionales la importancia de determinados sectores industriales, particularmente del bancario ${ }^{53}$, así como de sus propias entidades territoriales, ha impedido dejarlas a su suerte. Como resultado se ha alumbrado la conciencia de que el Estado terminará por acudir al rescate en caso de emergencia. En otras palabras, que existe una garantía pública latente.

Desde hace años, la ordenación de las finanzas públicas trata de evitar - con escaso éxito- que aquellas garantías públicas latentes se hagan efectivas. Muestra de ello es el artículo 125 TFUE, que prohíbe que la Unión o los Estados miembros asuman o respondan de los compromisos de otros Estados miembros, no obstante lo cual, ante la situación extrema de Grecia, diversos Estados miembros eludieron aquella prohibición mediante un acuerdo de préstamo para rescatar a Grecia el 8 de mayo de

51 M. SALVAdor ARMEndÁRIz (2010), «El riesgo sistémico en la regulación bancaria: una aproximación a las respuestas del derecho a la crisis financiera», en Revista Jurídica de Navarra, 50 (págs. 145-170).

52 «Europa no se hará de una vez ni en una obra de conjunto: se hará gracias a realizaciones concretas, que creen en primer lugar una solidaridad de hecho» (9.V.1950).

53 Viene al caso recordar que en el único caso en que un Estado no salió al rescate de uno de sus bancos, el 15 de septiembre de 2008 con Lehman Brothers, la economía mundial estuvo a punto de fracturarse. 
2010 (BOE 13.V.2010) ${ }^{54}$, así como se reformó el artículo 136 del Tratado para permitir la creación de un mecanismo de estabilidad que ejecutara los rescates. En España, la Ley General de Estabilidad Presupuestaria (Real Decreto Legislativo 2/2207) prohibió la asunción por el Estado de obligaciones contraídas por otras Administraciones (disposición adicional única), lo que no ha impedido la aprobación de distintos programas de pago a proveedores de las entidades locales y fondos de liquidez territorial con los que el Estado ha acabado sufragando obligaciones ajenas. A la existencia de estas garantías se refiere - con la denominación de implícitas-el preámbulo de la Ley 11/2015, de 18 de junio, de recuperación y resolución de entidades de crédito y empresas de servicios de inversión, que trata de evitar futuros rescates con fondos públicos: «Se persigue, en definitiva, resolver el viejo problema de las garantías públicas implícitas que protegerían a los acreedores de aquellas entidades que, por su relevancia en el sistema financiero, no serían en ningún caso liquidadas» ${ }^{55}$.

Ante la conciencia social de que existen unas garantías públicas latentes y de que los Estados contemporáneos difícilmente podrán evitar el rescate de las entidades e instituciones más relevantes, aquellos han reaccionado reforzando extraordinariamente sus poderes de intervención sobre los sectores más expuestos y susceptibles a los rescates: desde la UE se ha aprobado el control de las finanzas estatales y promovido la introducción de la estabilidad presupuestaria en las constituciones nacionales, el $\mathrm{BCE}$ ha asumido la supervisión de las entidades de crédito de la zona euro ${ }^{56}$, la UE y los Estados han endurecido extraordinariamente las exigencias de solvencia de las entidades de crédito, se han transformado las cajas de ahorro, se ha reformado el déficit de tarifa del sector eléctrico y, sin ánimo de extender más la enunciación, los fondos de liquidez autonómica y local se han acompañado de estrictas medidas de estabilidad presupuestaria y de información financiera al Estado.

La idea que subyace en estas nuevas regulaciones es que, dado que los poderes públicos pueden verse en la necesidad de rescatar entidades e instituciones estratégicas, consecuentemente deben contar con los poderes necesarios para evitar la repetición de aquellas situaciones en

54 Operativa que U. HÄDE (2012), Euro-Rettung zwischen Exekutivprimat und Parlamentsvorbehalt, Baden-Baden: Nomos (págs.15 y ss.), ha calificado de «huida al Derecho internacional».

55 A juicio de J. Esteve PARdo (2013), La nueva relación Entre Estado y sociedad. Aproximación al trasfondo de la crisis, Marcial Pons (págs. 135 y ss.), la reforma constitucional del artículo 135 opera como protección del Estado frente a los incesantes requerimientos de gasto propios de la sociedad contemporánea.

56 J. C. Laguna de Paz (2014), «El mecanismo europeo de supervisión bancaria», en Revista de Administración Pública, 194, págs. 49-79; C. CHINCHILla (2015), «El régimen de supervisión, inspección y sanción del Banco de España en la Ley 10/2014», en Revista Vasca de Administración Pública, 102, págs. 17-106 (págs. 72 y ss.). 
el futuro. Por esta vía, las garantías públicas están operando como incisivos títulos de intervención de los poderes públicos sobre la economía y otras entidades públicas ${ }^{57}$. Esto es, justifican que los poderes públicos que se han visto llamados a asumir los rescates ajenos acumulen potestades que con anterioridad no tenían para controlar los sectores rescatados, sean estos públicos o privados.

Estos modernos títulos de intervención han cristalizado en las nuevas regulaciones con dos notas características. La primera concierne al principio de proporcionalidad que se emplea tanto en la adopción de las medidas restrictivas como en el eventual control de estas. Así en el clásico escalonamiento de aquel principio —adecuación, necesidad y proporcionalidad ${ }^{58}$ - , la evitación de nuevos rescates con fondos públicos constituye una nueva finalidad que se incluye en el juicio de ponderación con mucho peso a la hora de justificar severas restricciones en la autonomía de la voluntad en el ámbito privado y la autonomía política o administrativa en el público.

La segunda característica consiste en una redistribución competencial que opera en sentido ascendente. El refuerzo de la fiscalización de la UE respecto de las finanzas nacionales; la asunción por el BCE de las competencias de supervisión bancaria ${ }^{59}$; o las medidas de control que el Estado ha adoptado sobre las finanzas autonómicas y locales, seguramente no se habrían producido sin los rescates con fondos públicos. Solo se explican porque la aceptación por una entidad territorial de un rescate con fondos ajenos constituye una quiebra en el diseño de la distribución competencial, así como en el ejercicio de las propias competencias, que necesitan ser completados con una intervención pública externa no prevista. Por su parte, las gravosas consecuencias presupuestarias que soporta el sujeto que avala o procura los fondos del rescate legitiman el rediseño competencial, con un refuerzo de las potestades de control económico sobre las instancias rescatadas.

57 Decía el profesor J. L. VILlar Palasí (1964), La intervención administrativa en la industria, Madrid: Instituto de Estudios Políticos (pág. 121), que el gran problema del derecho administrativo ha consistido desde sus comienzos en el hallazgo de títulos de potestad que legitimen la acción administrativa.

58 Véase por todos J. BARNES (1994), «Introducción al principio de proporcionalidad en el Derecho comparado y comunitario», en Revista de Administración Pública, 135, págs. 495-535 (págs. 521 y ss.); D. SARMiEnto (2004), El control de proporcionalidad de la actividad administrativa, Valencia: Tirant lo Blanch (págs. 314 y ss.); y M. CARLón (2010), «El principio de proporcionalidad», en J. A. Santamaría Pastor (dir.), Los principios jurídicos del derecho administrativo, Madrid: La Ley, págs. 203-230 (pág. 207).

$59 \mathrm{La}$ vinculación entre las medidas de rescate adoptadas por el BCE y la asunción de responsabilidades de supervisión bancaria la ha señalado M. IzQuiERdo CARRAsco (2012), "La supervisión pública sobre las entidades bancarias», en M. Rebollo Puig (dir.), La regulación económica. En especial, la regulación bancaria, Madrid: Iustel (págs. 207 y ss.). 


\section{Los rescates públicos y la cláusula de "economía de mercado»}

Finalmente, queda por dejar constancia de las implicaciones que la garantía del Estado tiene sobre la cláusula de economía de mercado contenida en los artículos 38 CE y 3.3 TUE.

Esta cláusula se sustenta en varios postulados fundamentales: el reconocimiento de la libertad de empresa — propiedad privada, poder de dirección de la empresa y autonomía de actuación en el mercado: publicidad, fijación de precios, oferta de productos, etc. ${ }^{60}$-; el sometimiento a la disciplina del mercado —el empresario queda a resultas del riesgo económico, haciendo suyas las ganancias o soportando las pérdidas-; y la premisa de que la actuación espontánea y libre de los operadores económicos beneficia al conjunto (la «mano invisible» de A. Smith). Tradicionalmente, la intervención pública ha incidido sobre el primer postulado ${ }^{61}$; en menor medida sobre el segundo, mediante regulaciones sobre defensa de la competencia, actividad de fomento o reconversión industrial; y, excepcionalmente sobre la premisa, como son las regulaciones concursales para la salida ordenada del mercado.

En coherencia, la aplicación del postulado de la disciplina de mercado a los sectores más golpeados por la crisis habría impuesto la disolución de las empresas que no fueran capaces de adaptarse a ella. Sin embargo, los rescates públicos han buscado impedir el natural desenvolvimiento de la cláusula de economía de mercado en los sectores estratégicos para que no se produjera aquel efecto indeseado. Con la particularidad de que en esta oportunidad, como consecuencia de la virulencia de la crisis y de la importancia de los sectores rescatados para el conjunto de la economía, la intervención pública se ha justificado en una finalidad novedosa. En efecto, tradicionalmente las intervenciones públicas sobre la disciplina del mercado se han justificado en la evitación de sus efectos secundarios más indeseados: nacionalizaciones de empresas, apoyo a industrias en declive (Ley 27/1984, de 25 de julio, de Reconversión y Reindustrialización) o apoyo a los sectores de población más afectados en aplicación de la cláusula de Estado social. Por el contrario, en esta crisis la intervención pública ha apuntado al núcleo mismo de la economía, rescatando los sectores estratégicos en preservación del funcionamiento económico de la sociedad. El Estado ha intervenido

60 F. OssenbüHL (1991), «Las libertades del empresario según la Ley Fundamental de Bonn», en Revista Española de Derecho Constitucional, 32 (págs. 9-44).

61 S. Martín-Retortillo (1988), Derecho administrativo económico I, Madrid: La Ley (págs. 84 y ss.); G. ARiño (2004), Principios de Derecho público económico, Granada: Comares (págs. 253 y ss.); y L. ArRoyo (2004), Libre empresa y títulos habilitantes, Madrid: CEPC (págs. 135 y ss.). 
principalmente para asegurar la continuidad del orden económico, la estabilidad económica a que se refiere el artículo 40 de la Constitución, y no simplemente para mitigar los efectos de la disciplina del mercado ${ }^{62}$.

Incluso se cuestiona la premisa de que la actuación libre y espontánea de los operadores económicos beneficie siempre al conjunto, al menos en el ámbito financiero, donde ha llegado a institucionalizarse la idea con la creación de un organismo de supervisión macroeconómica: la Junta Europea de Riesgo Sistémico ${ }^{63}$. Con anterioridad a la crisis, la intervención pública descansaba en la idea de que el conjunto del sistema financiero sería estable si cada una de sus entidades era solvente, por lo que la supervisión pública se organizó individualmente sobre estas últimas. Sin embargo, no se advirtió que en el conjunto de la economía se habían ido larvando unos desequilibrios económicos, que no eran detectables mediante el control de cada entidad individualmente considerada (pérdida de competitividad, endeudamiento excesivo, sobrevaloración de activos), y de tal magnitud que en pocos meses fueron capaces de revertir el sistema en su conjunto. A resultas de esta experiencia se ha arbitrado una supervisión macroeconómica, donde la Junta Europea ha sido encargada de advertir y dirigir recomendaciones a otras autoridades públicas sobre la formación de desequilibrios o riesgos latentes en el sector financiero que puedan poner en peligro el conjunto de la economía y, añadimos nosotros, que no se solventan con la actuación libre y espontánea de los operadores.

En fin, como ya se ha indicado, el derecho público de la economía que se viene formando en Europa desde hace varias décadas se nutre de principios, como el de sostenibilidad, tomados de otras regulaciones. Vemos ahora que la regulación económica también se vale de un nuevo principio, que es trasunto del clásico salus publica prima lex esto, y que impone como mandato prioritario a los Estados la evitación de la ruina económica general en la medida de sus posibilidades. Así pues, se abre paso una concepción renovada de la cláusula de economía de mercado, por la que se admite que las instancias públicas deben corregir el curso del mercado cuando resulte necesario para proteger la economía en su conjunto.

62 L. ARroyo (2004: 185-186 y 284) toma de la doctrina alemana la noción de «responsabilidad infraestructural» del Estado sobre la economía para explicar el mandato que los artículos 38 y 40 de la Constitución española imponen al Estado en el impulso económico y la función de garante respecto de las prestaciones de servicios de interés económico general.

63 Reglamento (UE) 1092/2010, del Parlamento Europeo y del Consejo, de 24 de noviembre de 2010, relativo a la supervisión macroprudencial del sistema financiero en la Unión Europea y por el que se crea una Junta Europea de Riesgo Sistémico. S. Flores DoÑa (2011), «La Junta Europea de riesgo sistémico», en Revista de Derecho Bancario y Bursátil, 121 (págs. 61-92). 
